\title{
Norfloxacin with itopride versus norfloxacin alone in secondary prophylaxis of spontaneous bacterial peritonitis: a randomized trial
}

\author{
Afaf Y. M. Younes ${ }^{1}$, Sherief Abd-Elsalam ${ }^{1 *}$ (D, Gehan F. Attia ${ }^{2}$ and Mona A. H. Shehata ${ }^{1}$
}

\begin{abstract}
Background: Bacterial translocation is considered the pathophysiological hallmark in the development of spontaneous bacterial peritonitis (SBP). Prokinetics can increase gastrointestinal (GIT) motility, reduce small bowel transit time, decrease bacterial translocation, and the possibility of SBP. The aim of this work was to compare the effectiveness and safety of itopride and norfloxacin versus norfloxacin only in secondary prophylaxis for cirrhotic ascitic patients with spontaneous bacterial peritonitis.
\end{abstract}

Results: Regarding the baseline clinical manifestations and laboratory investigations, there was no significant difference between both groups. The incidence of a recurrent SBP in group I, who had received itopride plus norfloxacin, reduced with a significant difference than other group II $(P=0.018)$. The median time for recurrence of SBP was highly longer in group I than group II with a significant difference $(P=0.042)$.

Conclusions: The combined usage of itopride with norfloxacin in patients with cirrhosis and ascites can decrease the occurrence of a recurrent SBP and significantly improve the survival of patients.

Trial registration: ClinicalTrials.gov Identifier: NCT04161768.

Keywords: Spontaneous bacterial peritonitis, Cirrhosis, Ascites, Prokinetics, Norfloxacin, Itopride

\section{Background}

Spontaneous bacterial peritonitis (SBP) is an ascitic fluid infection that occurs spontaneously with no overt source that can be remedied surgically. It is a common complication in cirrhotic patients with ascites. All cirrhotic patients with ascites are at risk of SBP. The occurrence of SBP is $1.5-3.5 \%$ in outpatients and is about $10 \%$ in hospitalized patients [1].

The most common life-threatening complication in patients with cirrhosis and ascites is SBP and the mortality rate ranges between 30 and 50\%; prompt diagnosis

\footnotetext{
* Correspondence: sherif_tropical@yahoo.com

1 Department of Tropical Medicine and Infectious Diseases, Faculty of

Medicine, Tanta University, Elbahr Street, Tanta 35111, Egypt

Full list of author information is available at the end of the article
}

and treatment are the most common variable causes in reducing morbidity and mortality from SBP [2].

When the number of polymorph nuclear cells was> 250 cells $/ \mathrm{mm}^{3}$ in ascitic fluid in the absence of the source of intra-abdominal infection, the diagnosis of SBP is established [1].

Variable factors are associated with the development of SBP but bacterial translocation is considered the pathophysiological hallmark in immune-compromised hosts in the pathogenesis of SBP [3].

SBP treatment is based on the administration of broad-spectrum empiric antibiotics such as thirdgeneration cephalosporins. For patients with beta-lactam allergy, alternatives include fluoroquinolones such as levofloxacin can be administered [4].
Springer Open

(c) The Author(s). 2021 Open Access This article is licensed under a Creative Commons Attribution 4.0 International License, which permits use, sharing, adaptation, distribution and reproduction in any medium or format, as long as you give appropriate credit to the original author(s) and the source, provide a link to the Creative Commons licence, and indicate if changes were made. The images or other third party material in this article are included in the article's Creative Commons licence, unless indicated otherwise in a credit line to the material. If material is not included in the article's Creative Commons licence and your intended use is not permitted by statutory regulation or exceeds the permitted use, you will need to obtain permission directly from the copyright holder. To view a copy of this licence, visit http://creativecommons.org/licenses/by/4.0/. 
Recently, it was found that prokinetics could increase GIT motility, decrease small bowel transit time and decrease small intestinal bacterial overgrowth (SIBO), so could decrease bacterial translocation and the possibility of SBP [5].

The aim of the work was to compare the effectiveness and the safety of itopride with norfloxacin versus norfloxacin only in secondary prevention of spontaneous bacterial peritonitis in cirrhotic ascitic patients.

\section{Methods}

This randomized study was conducted on 80 cirrhotic patients with ascites and previous episode of SBP attending to the Tropical Medicine Department of Tanta University Hospital in a time of 1 year since December 2018 toward December 2019. The committee of ethics of scientific research of Tanta Faculty of Medicine approved the studied protocol and written consents were obtained from the studied groups for participation. The study was registered on clinicaltrials.gov with a registration number NCT04161768. For comparing the 2 groups, we adopted simple randomization through computergenerated random numbers with equal allocation ratio by referring to a table of random numbers.

Patients with cirrhosis and ascites and with previous events of SBP who were diagnosed by pelvi-abdominal ultrasound, liver function tests, and ascitic fluid aspiration, and analysis were included in the study and all patients included in our study did not receive prokinetices before. However, patients with ascites due to causes other than cirrhosis, patients with hepatocellular carcinoma or any other neoplastic disorder, pregnant and lactating women, patients with recent antibiotic therapy in the 2 weeks before or patients with allergy or other contraindications of the used drugs were excluded from the study.

Patients in our study were randomized into 2 groups: group 1, cases who received itopride $150 \mathrm{mg}$ daily plus norfloxacin $400 \mathrm{mg}$ daily; group 2, patients who received norfloxacin $400 \mathrm{mg}$ daily alone. The two studied groups were followed up for 6 months, every 2 months for ascitic fluid analysis and when the clinical examination can be suggested SBP sings such as fever, tenderness, abdominal pain, or vomiting are present. The compliance was detected by asking the patients through their telephone numbers and by recovery of empty drug envelopes. Flow chart of the study is demonstrated in Fig. 1.

All patients were subjected for full history taking with attention on history of a previous attack of SBP, symptoms related to spontaneous bacterial peritonitis, history of treatment received through the 2 weeks before ascitic sample aspiration or history of the hepatic encephalopathy. Complete physical examination with attention on manifestations of advanced chronic liver disease.
Laboratory investigations was performed for all the patients enrolled in the study including complete blood count $(\mathrm{CBC})$, liver biochemical investigations, coagulation profile, kidney function assessments, serum Creactive protein (CRP), ascitic fluid chemical, physical and cytological analysis and culture, and the serumascites albumin gradient (SAAG). Pelvi-abdominal ultrasound was done for all patients to asses liver conditions and aspiration of ascitic fluid sample can be performed.

The primary end point was the percentage of patients who developed a recurrent attack of SBP at the end of six months follow up. The secondary end points were the mortality rate in both groups.

\section{Statistical analysis}

The collected data statistically analyzed by usage of the statistical package for social studies (SPSS) program. These numerical variables included (mean \pm SD) were calculated. The analysis of variance (ANOVA) was used to parallel of mean values between both groups. When ANOVA (F) value was significant, post hoc test (LSD) test could be used to assess the difference between both groups. The comparison of both groups was done by usage (chi-square-test $\left(\chi^{2}\right)$ to assess qualitative data; Student $t$ test to carry out the significance of the difference in two means of parametric data; and Mann-Whitney $U$ test to assess the significance of the difference in both variables of (numerical) non parametric data). The results were represented in tables and graphs. The level of significance was taken at $\mathrm{p}$ value of $<0.05$. P value is either non-significant (NS) if $>0.05$, significant $(\mathrm{S})$ if $<$ 0.05 , or highly significant $(\mathrm{HS})$ if $<0.001$ was calculated.

\section{Results}

Our study enrolled 80 patients, 46 men in addition to 34 women and their mean age was $57.50 \pm 6.48$ years for group I and $59.40 \pm 6.16$ years for group II (Table 1 ). As regard to the clinical manifestations which were present in both studied groups, there was no significant difference between both two groups. Regarding the laboratory investigations, there were no significant variances between both studied groups (Table 1).

The ascitic fluid culture of the two studied groups did not show significant difference between both groups. The most frequent organism in both groups was E. coli (Table 2).

Table 3 shows the incidence of recurrence of SBP and the cause of death in both groups. There was a significant increase in the occurrence of recurrent SBP in group II with $\mathrm{P}$ value $\left(\mathrm{P}=0.018^{*}\right)$. Also, the number of deaths showed a significant increase in group II $\mathrm{P}=$ 0.043 and SBP was significantly considered the main factor of death. Table 4 shows the median time for recurrence of SBP in the studied groups which was 


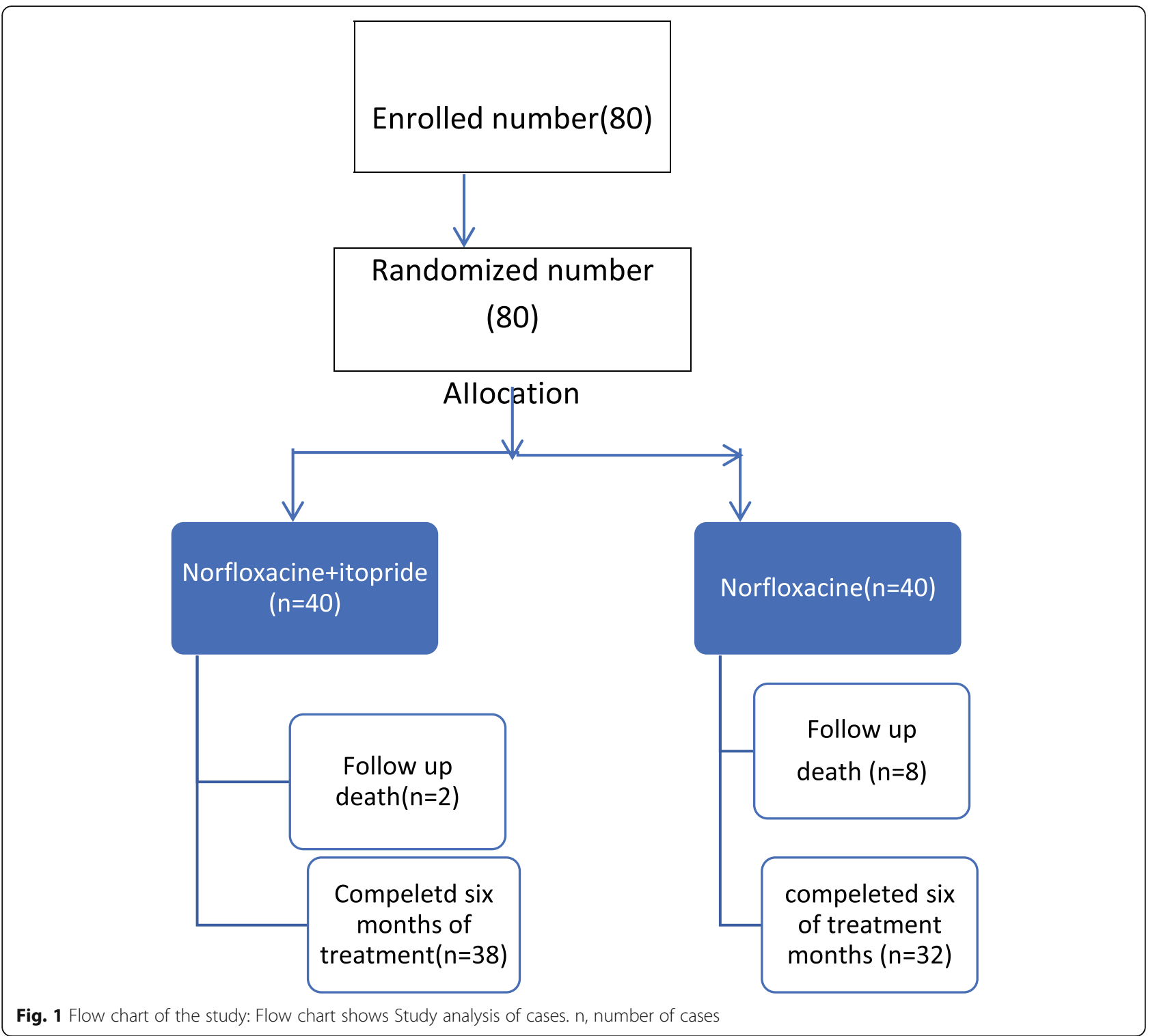

significantly longer in group I $\mathrm{P}=0.042 \%$. Figure 2 shows Kaplan-Meier survival curve which was used to assess the survival among the studied groups. Regarding the side effects of drugs, no side effects were reported by the included patients in both groups.

\section{Discussion}

The most common potential life-threatening complications in patients with cirrhosis and ascites is SBP where the mortality rate is alternating between 30 and 50\%; hence, the prompt diagnosis and treatment are the most common variable causes in reducing morbidity and mortality of SBP. Bacterial translocation is considered the pathophysiological hallmark in developing spontaneous bacterial peritonitis (SBP). Prokinetics can increase GIT motility, decrease small bowel transit time, decrease bacterial translocation and the possibility of SBP.

Our study was conducted for evaluating the effectiveness and safety of itopride, as a prokinetic drug, in cirrhotic patients with spontaneous bacterial peritonitis to detect its role in secondary prophylaxis of SBP.

The major strength of this study is that it shed a light about the role of prokinetics in prevention of SBP in cirrhotic ascitic cases through its effect on decreasing the probability of a bacterial overgrowth via increasing the intestinal motility.

In our study, we enrolled 80 cirrhotic ascitic cases with a previous event of SBP who were classified into two groups, each of 40 cases. SBP was common in males in the two studied groups ( 21 and 25 patients respectively). The mean age was $57.50 \pm 6.48$ years in group I and 
Table 1 Baseline demographic data, clinical manifestations, and the laboratory investigations of both groups

\begin{tabular}{|c|c|c|c|c|}
\hline & $\begin{array}{l}\text { Group I (itopride + norfloxacin) (number= } \\
40) \\
\text { No. }(\%)\end{array}$ & $\begin{array}{l}\text { Group II (norfloxacin) (number= } \\
40) \\
\text { No. (\%) }\end{array}$ & $\begin{array}{l}\text { Test of } \\
\text { sig }\end{array}$ & $\begin{array}{l}P \\
\text { value }\end{array}$ \\
\hline Age (years) (mean \pm SD) & $57.50 \pm 6.48$ & $59.40 \pm 6.16$ & $t=1.34$ & 0.183 \\
\hline \multicolumn{5}{|l|}{ Gender } \\
\hline Male & $21(52.5)$ & $25(62.5)$ & $x^{2}=0.81$ & 0.366 \\
\hline Female & $19(47.5)$ & $15(37.5)$ & & \\
\hline Abdominal pain & $39(97.5)$ & $37(92.5)$ & $\mathrm{FE}=1.05$ & 0.615 \\
\hline Fever & $31(77.5)$ & $34(85.0)$ & $x^{2}=0.73$ & 0.390 \\
\hline Hepatic encephalopathy & $8(20.0)$ & $9(22.5)$ & $x^{2}=0.07$ & 0.785 \\
\hline Hemoglobin (g/dl) & $10.33 \pm 1.34$ & $9.83 \pm 1.10$ & $\mathrm{t}=1.82$ & 0.072 \\
\hline Platelets (cell× 103/mm³) & $122.67 \pm 73.03$ & $146.62 \pm 77.41$ & $U=1.54$ & 0.122 \\
\hline $\begin{array}{l}\text { Total leucocytic count (cell× 103/ } \\
\mathrm{mm}^{3} \text { ) }\end{array}$ & $5.85 \pm 3.42$ & $6.51 \pm 4.58$ & $U=0.476$ & 0.634 \\
\hline S. creatinine (mg/dl) & $1.08 \pm 0.58$ & $1.16 \pm 0.40$ & $U=1.61$ & 0.106 \\
\hline S urea $(\mathrm{mg} / \mathrm{dl})$ & $56.47 \pm 41.81$ & $52.19 \pm 29.86$ & $\mathrm{U}=0.09$ & 0.923 \\
\hline AST (u/l) & $52.67 \pm 36.43$ & $50.70 \pm 33.67$ & $U=0.24$ & 0.810 \\
\hline $\mathrm{ALT}(\mathrm{u} / \mathrm{l})$ & $41.82 \pm 27.27$ & $36.62 \pm 17.36$ & $U=0.28$ & 0.776 \\
\hline S. albumin (g/dl) & $2.51 \pm 0.50$ & $2.61 \pm 0.41$ & $\mathrm{t}=0.97$ & 0.335 \\
\hline S. Bilirubin (mg/dl) & $2.80 \pm 2.68$ & $3.82 \pm 3.69$ & $\mathrm{U}=0.90$ & 0.368 \\
\hline INR & $1.56 \pm 0.42$ & $1.65 \pm 0.45$ & $\mathrm{t}=0.86$ & 0.389 \\
\hline CRP (mg/l) & $38.86 \pm 37.59$ & $31.00 \pm 24.56$ & $U=0.45$ & 0.649 \\
\hline
\end{tabular}

$59.40 \pm 6.16$ years in group II without any a significant difference in both studied groups in age and sex distribution. The two groups were mostly cross-matched.

In this study, the most common symptoms of SBP which presented in both groups were abdominal pain in 39 patients $(97.5 \%)$ in group I but in 37 cases $(92.5 \%)$ in group II and fever presented in 31 patients (77.5\%) through group I but 34 cases $(85 \%)$ in group II then vomiting and hepatic encephalopathy $(22.5 \%$ and $20 \%$ respectively) of group I and $40 \%$ and $22.5 \%$ respectively of group II without a significant differences in both studied groups as regards the clinical manifestations plus laboratory characteristics of our studied patients. This shows that the patients of both studied groups are cross matched.

In the current work, the degree of ascites in SBP patients was either moderate up or marked. Moderate ascites presented in 32 cases $80 \%$ (group I) while (group II) the moderate ascites was detected in 17 cases (42\%), while marked ascites was reported in $20 \%$ and $57.5 \%$ of

Table 2 The patients' ascitic fluid culture analysis

\begin{tabular}{llll}
\hline & $\begin{array}{l}\text { Group I } \\
\text { Number of cases } \\
\text { No. (\%) }\end{array}$ & $\begin{array}{l}\text { Group II } \\
\text { Number of cases } \\
\text { No. (\%) }\end{array}$ & Test of sig \\
\hline $\begin{array}{l}\text { Culture result } \\
\text { Positive }\end{array}$ & $32(80.0)$ & $31(77.5)$ & $X^{2}=0.07$ \\
Negative & $8(20.0)$ & $9(22.5)$ & 0.765 \\
Organisms & $16(50.0)$ & $14(45.2)$ & FE=0.27 \\
$\begin{array}{ll}\text { E. coli -G-ve } \\
\text { Klebesiella- G-ve }\end{array}$ & $8(25.0)$ & $9(29.03)$ & \\
Proteous- G-ve & $4(12.5)$ & $4(12.9)$ & \\
Staph- G+ve & $4(12.5)$ & $3(9.6)$ & 0.965 \\
\hline
\end{tabular}

$\mathrm{X}^{2}$ chi squared test, $F E$ Fisher's exact test

*Significant 
Table 3 Incidence of SBP recurrence and causes of death in both groups

\begin{tabular}{|c|c|c|c|c|}
\hline Time & $\begin{array}{l}\text { Group I } \\
\text { number } \\
\text { No. (\%) }\end{array}$ & $\begin{array}{l}\text { Group II } \\
\text { number } \\
\text { No. (\%) }\end{array}$ & $x^{2}$ & $P$ value \\
\hline \multicolumn{5}{|c|}{ 2nd month $(n=80)$} \\
\hline SBP free & 35 (87.5) & $26(65.0)$ & 5.59 & $0.018^{*}$ \\
\hline SBP & $5(12.5)$ & $14(35.0)$ & & \\
\hline \multicolumn{5}{|c|}{ 4th month $(n=72)$} \\
\hline SBP free & $34(89.5)$ & $25(73.5)$ & 3.08 & 0.079 \\
\hline SBP & $4(10.5)$ & $9(26.5)$ & & \\
\hline \multicolumn{5}{|c|}{ 6th months $(n=70)$} \\
\hline SBP free & $34(87.5)$ & $23(71.8)$ & 2.49 & 0.094 \\
\hline SBP & $4(12.5)$ & $9(28.1)$ & & \\
\hline \multicolumn{5}{|c|}{ Fate (end study) } \\
\hline Alive & $38(95.0)$ & $32(80.0)$ & & $0.043^{*}$ \\
\hline Dead & $2(5.0)$ & $8(20.0)$ & 4.11 & \\
\hline \multicolumn{5}{|c|}{ Causes of death } \\
\hline HRS & $2(5.0)$ & $5(12.5)$ & 2.94 & 0.230 \\
\hline SBP & $0(0.0)$ & $6(15.0)$ & & \\
\hline $\mathrm{HE}$ & $0(0.0)$ & $3(7.5)$ & & \\
\hline
\end{tabular}

*Significant

group I and II respectively with no statistically significant difference in group I and group II. These results corroborate the ideas of [6] who stated that ascitic fluid infection mostly developed when the ascitic fluid volume was at its maximum.

In the current study, patient groups showed low serum albumin level but high serum bilirubin, INR, AST, and ALT levels which mean the most reported cases of that disease (SBP) were Child-Pugh class $\mathrm{C}$ in both groups without a statistically significant variance in the studied groups [7].

Diagnostic paracentesis is the main stay in SBP diagnosis and can differ in SBP from secondary peritonitis [8]. It was performed to all cases in groups I and II included in this study. There was no statistically significant variance in the two patient groups according to the ascitic fluid analysis.

Table 4 Median time of recurrence of spontaneous bacterial peritonitis between both studied groups

\begin{tabular}{|c|c|c|c|c|c|}
\hline \multirow[t]{3}{*}{ Group } & \multicolumn{3}{|c|}{ Mean time (month) } & \multirow{3}{*}{$\begin{array}{l}\text { Log- } \\
\text { rank } \\
\text { test }\end{array}$} & \multirow{3}{*}{$\begin{array}{l}P \\
\text { value }\end{array}$} \\
\hline & \multirow[t]{2}{*}{ Estimate } & \multicolumn{2}{|l|}{$95 \% \mathrm{Cl}$} & & \\
\hline & & Lower & Upper & & \\
\hline Group I (n=39) & 5.76 & 5.41 & 6.12 & 4.14 & $0.042^{*}$ \\
\hline Group II $(n=36)$ & 5.42 & 4.90 & 5.94 & & \\
\hline Overall & 5.57 & 5.26 & 5.87 & & \\
\hline
\end{tabular}

*Significant
The mean value of serum-ascites albumin gradient (SAAG) in our current study was $>1.1 \mathrm{~g} / \mathrm{dl}$ in both patient groups which confirmed that the etiology of ascites was portal hypertension in our SBP patients. Agarwal et al. [9] stated that SAAG levels of $>1.1 \mathrm{~g} / \mathrm{dl}$ confirms that ascites is because of portal hypertension regardless the infection.

As regards to the ascitic fluid culture, the most reported cases of SBP, in both groups, were positive for gram-negative cocci without a statistical significant difference between both groups. These results did not match with Mostafa et al. [10] who found that the majority of their cases of SBP because of gram-positive cocci. In our study, we found that the most common and virulent organisms isolated from the cases were Escherichia coli species and Klebesiella but the less common was Staph-Gram-positive cocci, this matched with Novella et al. [11] who observed that of E. coli was isolated in $90 \%$ of their SBP patients.

In our study, on follow-up of the studied SBP patients, we observed, at the second month, a total of 14 episodes (35\%) of recurrent SBP infections in group II (norfloxacin only) versus 5 episodes (12.5\%) in group I (norfloxacin plus itopride) with an apparent statistically significant difference. The same variance was also detected in both studied groups in that fourth and sixth month follow-up; however, this difference was not significant. So the usage of both norfloxacin plus itopride (group I ) showed a better SBP incidence free through the study follow-up period being $87.5 \%$, 89.5, and $87.5 \%$ on the follow-up periods at second, fourth, and sixth month respectively, as compared to that, on usage of norfloxacin only as a SBP secondary prophylactic measure in group II. This accompanied with death of $20 \%$ of group II cases compared to death of only $5 \%$ of group I cases through the fourth and sixth months follow-up.

According to the present results, regarding the percentage of patients in group I (under treatment with norfloxacin plus itopride) who developed recurrent SBP which represented $12.5 \%, 10.5 \%$, and $12.5 \%$ of cases through the follow-up period at the second, fourth, and sixth months respectively. As a probable explanation for the developing of SBP by the translocation of the bacteria from the intra (intestine) to extra (ascitic fluid) could not be the only route of infection, and the presence of ascitic bacterial DNA can support that condition [12].

In the present study, we reported a $65 \%, 73.5 \%$, and $71.9 \%$ of SBP incidence free through the second, fourth, and sixth months follow-up period respectively in group II who received norfloxacin only. This result matched with Ghafar et al. [13] study that evaluated norfloxacin use in prophylaxis of SBP that established $40 \%$ decreasing in the frequency of SBP, among their patients. Also, 


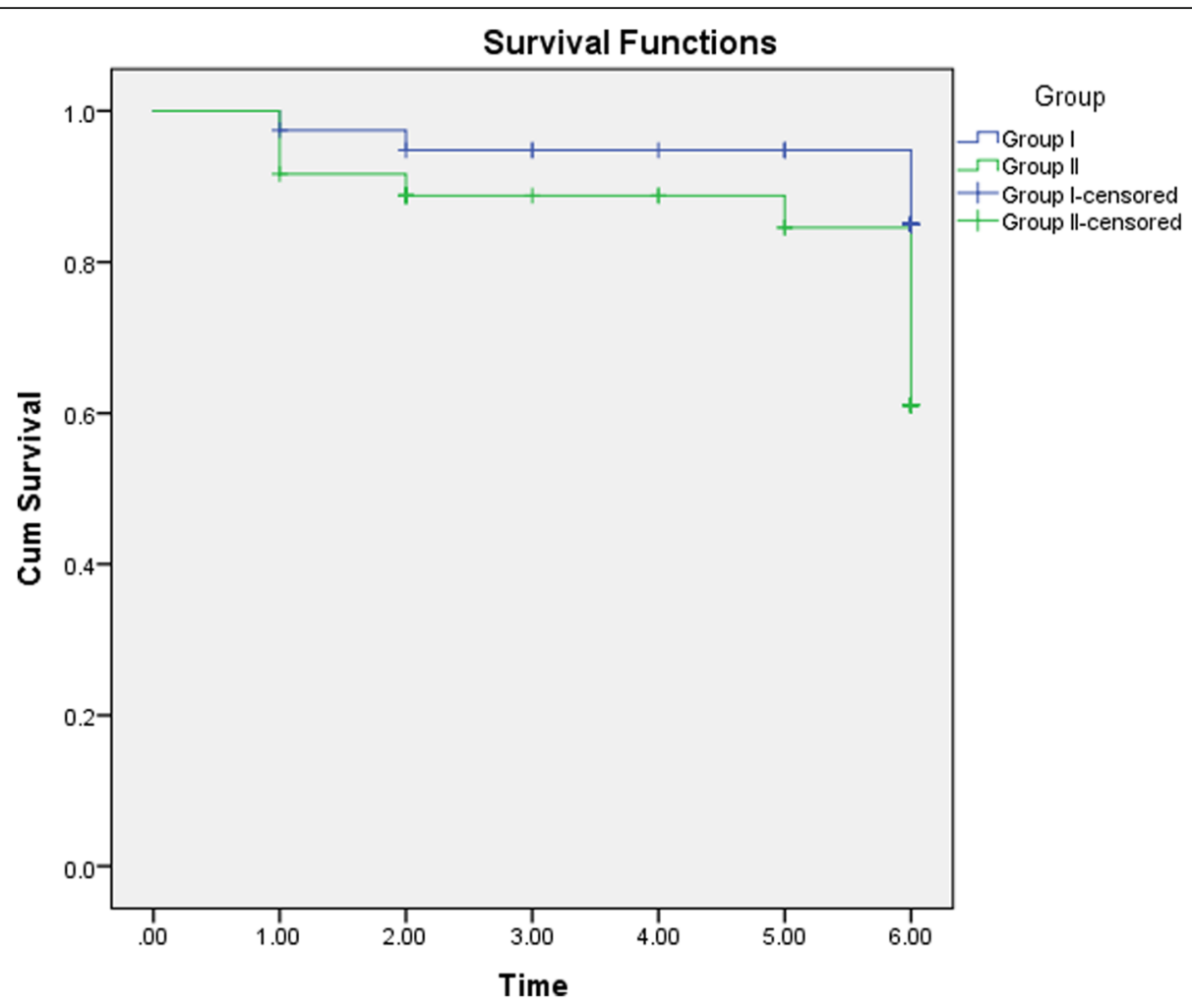

Fig. 2 Disease free (SBP free) survival (in months) by Kaplan-Meier analysis at 6 months

Hanouneh et al. [14] found 72\% prevention rates of SBP in their study.

On the other hand, Fernandez et al.'s [15] work showed that $93 \%$ reducing in the SBP incidence cases, who received norfloxacin. This difference might be due to the type of patients included in our study or the prophylaxis of SBP with norfloxacin only becomes less active as before, because of increasing the incidence of quinolones bacterial resistance in cirrhotic patients flora in the stool due to over use of these drugs [16].

In the current study, the median time for recurrent SBP development was a highly significant prolonged in group I when we compared it by the group II. This was associated with a statistically significant improvement in patient survival rate. The recurrent SBP development rate was significantly decreased in group I (5\%) when we compared that by the other group (II) (20\%) and that difference in the incidence of SBP recurrence occurred in only in the first 2 months of follow-up due to the number of patient's death increased through the last 4 months that was mainly due to recurrent SBP (15\%), HRS (12.5\%), and hepatic encephalopathy (7.5\%) in group II. While only HRS was reported as the only cause of death in $5 \%$ of group I. These results highlight the advantage of using the prokinetics agents (itopride) in combination with norfloxacin in SBP secondary prophylaxis.
The most common causes of mortality allover our study were hepatic encephalopathy, sepsis, and hepatorenal syndrome. And the results showed the beneficial effect of prokinetices (itopride) on group I cases that death in this group was $5 \%$ only compared to $20 \%$ death rate in group II.

On the same hand, PC Revaiah et al. [17] reported that combined use of prokinetics drugs could considerably reduce the possibility of small intestinal bacterial over growth because of increasing the intestinal motility, which lead to reduce bacterial translocation, the path of bacteria from the intra (intestine) to extra-intestinal such as ascitic fluid and this condition can be useful in SBP prophylaxis and treatment approach.

On other hand, Frazee et al. [18] found that long-term antimicrobial prophylaxis may be useful and has a benefit in cirrhotic patients. However, the magnitude of the benefits was less and the frequency of overall infections and mortality did not change [19].

In the current study, we did not report any side effects from usage of itopride which supported by Huang X (2012), [20] who found that itopride was the least prokinetics agent side effects through the incidence rate of its side effects. Also, itopride had an excitatory influence on the small and large intestine better than cisapride or mosapride [21].

The main limitation of this study is being a single center study with a problem of generalizing the findings. Therefore, larger multicenter studies are crucially 
needed to document the role of prokinetic drugs in prevention of SBP.

\section{Conclusions}

Norfloxacin plus itopride (alkapride) prophylaxis reduced the possibility of development of recurrent SBP in addition to hepatorenal syndrome (HRS) which can precipitated by SBP and that clue why combined therapy improved HRS. This regimen can improve the survival rate in cirrhotic ascitic patients.

\section{Abbreviations}

Alb: Albumin; ALT: Alanine transaminase; AST: Aspartate transaminase; BMI: Body mass index; CBC: Complete blood count; DM: Diabetes mellitus; Hb: Hemoglobin; HBV: Hepatitis B virus; HCV: Hepatitis C virus; HTN: Hypertension; No.: Number; PCR: Polymerase chain reaction; PLT: Platelets; SBP: Spontaneous bacterial peritonitis; SD: Standard deviation; SVR: Sustained virological response; WBCs: White blood cells

\section{Acknowledgements}

The authors acknowledge all patients participated in this study and take responsibility for all aspects of the reliability and freedom from bias of the data presented and their discussed interpretation.

\section{Authors' contributions}

SA designed the study. SA and MAHS developed the methodology, AYMY, MAHS, and SA wrote the manuscript. AYMY, MAHS, GFA, and SA collected the data. All the authors participated sufficiently in the work and approved the final version of the manuscript. The authors have read and approved the manuscript.

\section{Funding}

This research received no specific grant from any funding agency in the public, commercial, or not-for-profit sectors.

\section{Availability of data and materials}

The authors' institution does not allow public data access.

\section{Declarations}

\section{Ethics approval and consent to participate}

The research was approved from Tanta University Faculty of medicine Research ethical committee with approval code 30766/7/18. The research also was approved by the ministry of health research ethical committee. An informed written consent was taken from each patient. The study protocol complies with the ethical guidelines of the 1975 Declaration of Helsinki as reflected in prior approval by the institution's Human Research Committee.

\section{Consent for publication}

Not applicable.

\section{Competing interests}

The authors declare that there is no conflict of interest.

\section{Author details}

${ }^{1}$ Department of Tropical Medicine and Infectious Diseases, Faculty of Medicine, Tanta University, Elbahr Street, Tanta 35111, Egypt. ²Department of Clinical Pathology, Faculty of Medicine, Tanta University, Tanta, Egypt.

Received: 14 January 2021 Accepted: 3 May 2021

Published online: 10 May 2021

\section{References}

1. European Association for the Study of the Liver (EASL) (2018). EASL recommendations on treatment of hepatitis C 2018. J Hepatol.2018.

2. Thevenot T, Cadranel JF, Nguyen- Khac E, Tilmant L, Tiry C (2004) Diagnosis of spontaneous bacterial peritonitis in cirrhotic patients by use of two reagent strips. Eur J Gastro enterol Hepatol 16(16):579-583
3. Wiest R, Krag A and Gerbes A.(2012): Spontaneous bacterial peritonitis: recent guidelines and beyond. Gut. 2012; 61:297-310, 2, doi: https:/doi. org/10.1136/gutjnl-2011-300779.

4. Kim J, Tsukamoto M, Mathur A (2014) Delayed paracentesis is associated withincreased in-hospital mortality in patients with spontaneous bacterialperitonitis. Am J Gastroenterol 109(9):1436-1442. https://doi.org/1 0.1038/ajg.2014.212

5. Arroyo V, Garcia-Martinez R, Salvatella X (2014) Human serum albumin, systemic inflammation, and cirrhosis. J Hepatol 61(2):396-407. https://doi. org/10.1016/j.jhep.2014.04.012

6. Runyon BA (2002) Strips and tubes: improving the diagnosis of spontaneous bacterial peritonitis. Hepatology 37(4):745-747

7. Paul K, Kaur J, Kazal HL (2015) To study the incidence, predictive factors and clinical outcome of spontaneous bacterial peritonitis in patients of cirrhosis with ascites. J Clin Diagn Res 9(7):9-12

8. Green TE, Bandy SM. (2015): Spontaneous bacterial peritonitis work up (online accessed 11 April 2016) URL: http://emedicine.medscape.com/a rticle/789105-workup.

9. Agarwal MP, Choudhury BR, Banerjee BD, Kumar A (2008) Ascitic fluid examination for diagnosis of spontaneous bacterial peritonitis in cirrhotic ascites. J Indian Acad Clin Med 9(1):29-32

10. Mostafa MS, El-Seidi EA, Kassem AM, Shemis MA, Saber M, Michael MN (2015) Detection of ascitic fluid infections in patients with liver cirrhosis and ascites. Arab J Gastroenterol 12(1):20-24

11. Novella M, Solà R, Soriano G, Andreu M, Gana J, Ortiz J et al (1997) Continuous vs. inpatient prophylaxis of the first episode of spontaneous bacterial peritonitis in cirrhotic patients with norfloxacin. Hepatology 25(3): 532-536. https://doi.org/10.1002/hep.510250306

12. Rogers GB, van der Gast CJ, Bruce KD, Marsh P (2013) Ascitic microbiota composition is correlated with clinical severity in cirrhosis with portal hypertension. Plos One 8(9):e74884. https://doi.org/10.1371/journal.pone. 0074884

13. Ghafara AA, Salah R, Ahmed A (2019) Rifaximin plus norfloxacin versus norfloxacin alone in primary prophylaxis of spontaneous bacterial peritonitis in patients with variceal bleeding. Egypt J Intern Med 31(3):281-287. https:// doi.org/10.4103/ejim.ejim_6_19

14. Hanouneh MA, Hanouneh IA, Hashash JG, Law R, Esfeh JM, Lopez R et al (2012) The role of rifaximin in the primary prophylaxis of spontaneous bacterial peritonitis in patients with liver cirrhosis. J Clin Gastroenterol 46: 709-715

15. Fernandez J, Navasa M, Planas R, Montoliu S, Monfort D, Soriano G et al (2007) Primary prophylaxis of spontaneous bacterial peritonitis delays hepatorenal syndrome and improves survival in cirrhosis. Gastroenterology 133(3):818-824. https://doi.org/10.1053/j.gastro.2007.06.065

16. Fernandez J, Navasa J, Colmenero J (2002) Bacterial infections in cirrhosis: epidemiological changes with invasive procedures and norfloxacin prophylaxis. Hepatol 35(1):140-148. https://doi.org/10.1053/jhep.2002.30082

17. Revaiah PC, Kochhar R, Rana SV, Berry N, Ashat M, Dhaka N et al (2018) Risk of small intestinal bacterial overgrowth in patients receiving proton pump inhibitors versus proton pump inhibitors plus prokinetics. J Gastroenterol Hepatol 33:47-53

18. Frazee LA, Marinos AE, Rybarczyk AM, Fulton SA (2005) Long-term prophylaxis of spontaneous bacterial peritonitis in patients with cirrhosis. Ann Pharmacother 39(5):908-912. https://doi.org/10.1345/aph.1E585

19. Assem M, Elsabaawy M, Abdelrashed M (2016) Efficacy and safety of alternating norfloxacin and rifaximin as primary prophylaxis for spontaneous bacterial peritonitis in cirrhotic ascites: a prospective randomized open-label comparative multicenter study. Hepatol Int 10:377-385

20. Huang X, Lv B, Zhang S, Fan YH, Meng LN (2012) "Itopride therapy for functional dyspepsia: a meta-analysis".World. J Gastroenterol 18(48):73717377

21. Lim HC, Kim YG, Lim JH, Kim HS, Park H (2008) Effect of itopride hydrochloride on the ileal and colonic motility in guinea pig in vitro. Yonsei Med J 49:3

\section{Publisher's Note}

Springer Nature remains neutral with regard to jurisdictional claims in published maps and institutional affiliations. 